\title{
REVIEW
}

\section{Proprotein Convertase Subtilisin/Kexin Type 9}

\section{$A$ View beyond the Canonical Cholesterol-Lowering Impact}

\author{
Chiara Macchi, ${ }^{*}$ Nicola Ferri, ${ }^{\dagger}$ Cesare R. Sirtori, ${ }^{*}$ Alberto Corsini, ${ }^{*}$ Maciej Banach,,${ }^{\natural \mathbb{\Psi}}$ and Massimiliano Ruscica*
}

From the Department of Pharmacological and Biomolecular Sciences, * Universita' degli Studi di Milano, Italy; the Department of Pharmaceutical and Pharmacological Sciences, ${ }^{\dagger}$ University of Padova, Padua, Italy; the Istituti di Ricovero e Cura a Carattere Scientifico MultiMedica, ${ }^{\ddagger}$ Sesto San Giovanni/ Milan, Italy; the Department of Hypertension, ${ }^{\S}$ Medical University of Lodz, Lodz, Poland; the Polish Mother's Memorial Hospital Research Institute, "Lodz, Poland; and the Cardiovascular Research Centre," University of Zielona Góra, Zielona Góra, Poland

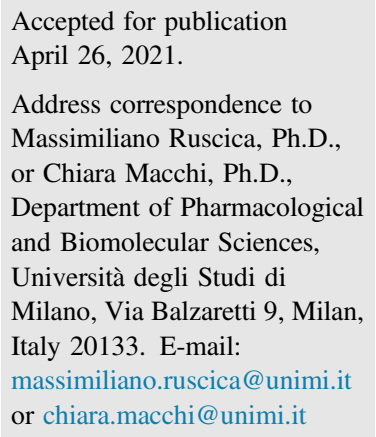

\begin{abstract}
Proprotein convertase subtilisin/kexin type 9 (PCSK9), mainly synthetized and released by the liver, represents one of the key regulators of low-density lipoprotein cholesterol. Although genetic and interventional studies have demonstrated that lowering PCSK9 levels corresponds to a cardiovascular benefit, identification of non-cholesterol-related processes has emerged since its discovery. Besides liver, PCSK9 is also expressed in many tissues (eg, intestine, endocrine pancreas, and brain). The aim of the present review is to describe and discuss PCSK9 pathophysiology and possible non-lipid-lowering effects whether already extensively characterized (eg, inflammatory burden of atherosclerosis, triglyceride-rich lipoprotein metabolism, and platelet activation), or to be unraveled (eg, in adipose tissue). The identification of novel transcriptional factors in the promoter region of human PCSK9 (eg, ChREBP) characterizes new mechanisms explaining how controlling intrahepatic glucose may be a therapeutic strategy to reduce cardiovascular risk in type 2 diabetes. Finally, the evidence describing PCSK9 as involved in cell proliferation and apoptosis raises the possibility of this protein being involved in cancer risk. (Am J Pathol 2021, 191: 1385-1397; https://doi.org/10.1016/j.ajpath.2021.04.016)
\end{abstract}

The story of proprotein convertase subtilisin/kexin type 9 (PCSK9) started in 2003 when Abifadel et al ${ }^{1}$ described two gain-of-function (GOF) mutations in the PCSK9 gene (S127R and $F 216 L$ ), both associated with autosomal dominant hypercholesterolemia. Since then, $>220$ PCSK9 variants have been reported. PCSK 9 has been classified as the third gene associated with familial autosomal dominant hypercholesterolemia, with an estimated incidence around $2.3 \%$; and for variants for low-density lipoprotein receptor $(L D L R)$ and apolipoprotein $\mathrm{B}(a p o B)$ an incidence of approximately $67 \%$ and $14 \%$, respectively. Three loss-offunction (LOF) nonsense mutations (Y142X,C679X, and $R 46 L$ ) have been identified. ${ }^{2}$ On the basis of genetic studies reporting that carriers of LOF variants for PCSK9 exhibit low levels of LDL with a reduction in the risk of myocardial infarction, fatal coronary heart diseases, or coronary revascularizations, ${ }^{2}$ the Food and Drug Administration approved two monoclonal antibodies (evolocumab and alirocumab) for the treatment of hypercholesterolemias,
$<12$ years after the gene discovery. In 2020, the European Medical Agency approved the first silencing RNA therapy against PCSK9 (inclisiran).

Besides regulating LDL cholesterol homeostasis, a role of PCSK9 in non-cholesterol-related processes has emerged. Although mainly derived from the liver, ${ }^{3}$ PCSK9 9 is expressed in other tissues (eg, intestine, pancreas, and central nervous system) and cell types (eg, macrophages). The use of transgenic animal models has provided evidence that, in addition to LDLR, PCSK9 seems to degrade other receptors (eg, CD36), thus implying a direct involvement in endothelial function, inflammation, and hemostasis. In spite of safety data from clinical trials, mendelian randomization analyses have highlighted a higher risk of developing new-onset diabetes in carriers of PCSK9 LOF variants. ${ }^{4}$ Finally, considering that

\footnotetext{
Supported by the Cariplo Foundation 2018-0511 (M.R.) and Fondazione Carlo Sirtori 2021 (C.R.S.).

Disclosures: None declared.
} 
PCSK9 was initially identified as an uncharacterized brain subtilase called neural apoptosis-regulated convertase-1 (NARC1), ${ }^{5}$ transiently expressed in the growing telencephalon and cerebellum, its potential effects on the central nervous system are as yet not clear.

Thus, the aim of the present review is to describe the molecular mechanisms beyond cholesterol lowering and to discuss the clinical implications of expected and unexpected effects of a therapeutic approach leading to undetectable circulating PCSK9 levels. Research strategies comprised the use of pubmed.gov and selection of articles in English. The following search parameters were used: PCSK9 or NARC1 AND adipose tissue AND atherosclerosis AND brain AND coagulation AND inflammation-related atherosclerosis AND intestine AND triglyceride-rich lipoproteins AND major adverse cardiovascular events AND pancreas AND platelet AND tumors. C.M. and M.R. screened titles and full text of articles identified in this search.

\section{The Biology}

Human PCSK9 encodes a 692-amino acid glycoprotein with an overall domain structure similar to other proprotein convertase family members. PCSK9 includes a signal peptide, a prodomain, a subtilisin-like catalytic domain, and a variable $\mathrm{C}$-terminal domain with a fold that has never been observed in subtilisin-like serine proteases. ${ }^{6}$ As depicted in
Figure 1, PCSK9 contains a catalytic triad (Asp ${ }^{186}$, $\mathrm{His}^{226}$, and $\mathrm{Ser}^{386}$ ) superimposable on the catalytic triads of other subtilisins. ${ }^{5,7}$ PCSK9 processing occurs in the secretory pathway, and the autocleavage generates a stable PCSK9 heterodimer composed of a prodomain fragment (amino acids 32 to $152 ; 13 \mathrm{kDa}$ ) and a mature $62-\mathrm{kDa}$ fragment containing the catalytic and C-terminal domains. ${ }^{8}$ The prodomain serves a dual role: as a chaperone for folding and as an inhibitor of catalytic activity. The cysteine-histidine rich domain of the C-terminal domain is a critical determinant for cellular degradation of LDLR $^{9}$ and PCSK9 secretion. ${ }^{10}$ Once secreted at the cell surface, PCSK9 interacts directly with the epidermal growth factor repeat A domain of the LDLR, ${ }^{11}$ thus favoring its degradation through an extracellular route implicating clathrin heavy chain-mediated endocytosis. An intracellular route has also been identified: PCSK9 fosters LDLR degradation by binding and shuttling LDLR from the trans-Golgi network directly to lysosomes involving clathrin light chains. ${ }^{12}$ PCSK9-induced endocytosis and lysosomal degradation of LDLR are also mediated by caveolin but not by clathrin, in a cyclaseassociated protein 1-dependent manner ${ }^{13}$ (Figure 2). PCSK9 can also play a role in LDLR maturation. ${ }^{14}$ In more extreme experimental conditions (ie, in the case of PCSK9 adenoviral infections), a second intracellular pathway associated with LDLR degradation has been observed within the post-endoplasmic reticulum (ER) compartments
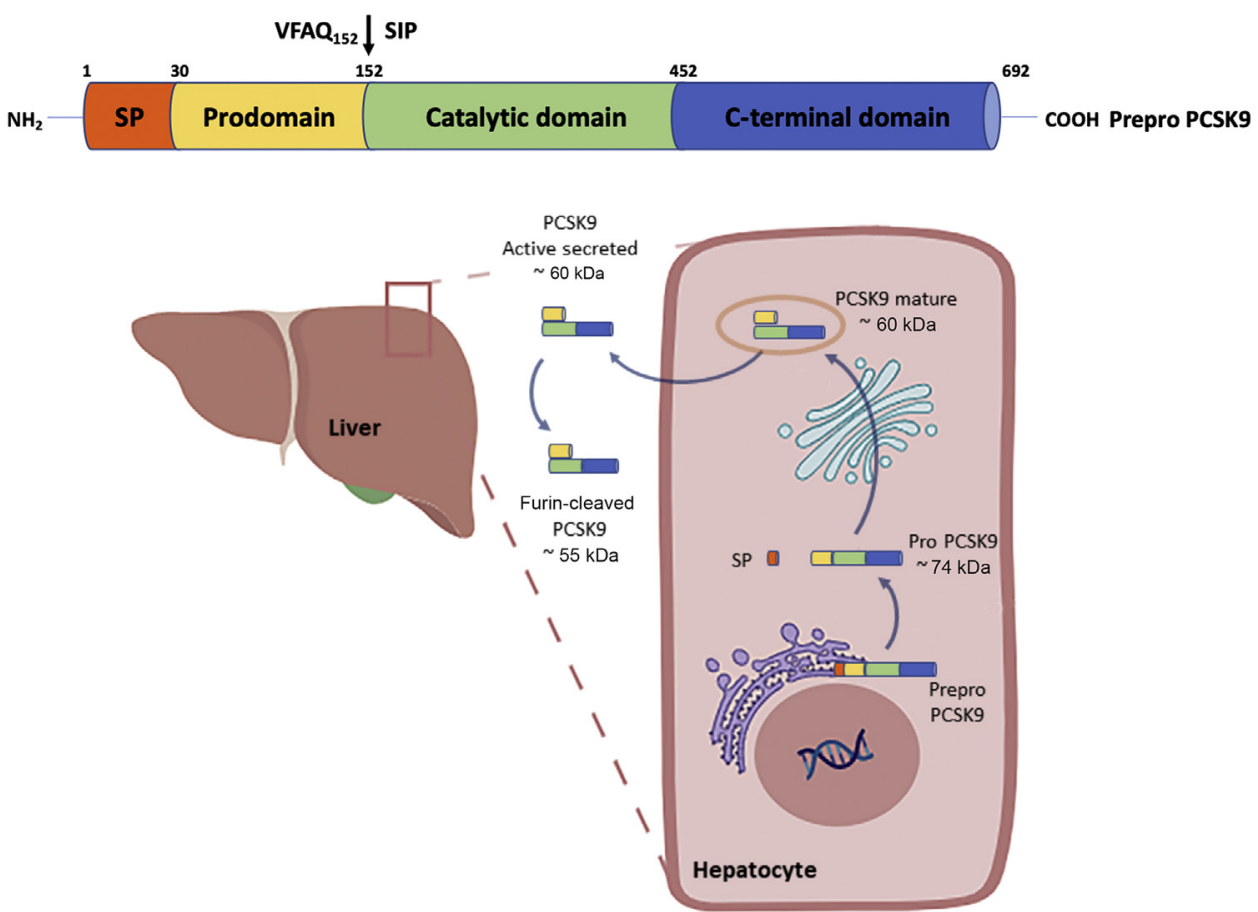

Figure 1 The mature form of proprotein convertase subtilisin kexin type 9 (PCSK9) consists of a signal peptide [amino acids (aa) 1 to 30], a prodomain (aa 31 to 152), a catalytic domain (aa 153 to 452), and a C-terminal domain (aa 453 to 692). Once in the endoplasmic reticulum, the signal peptide is cleaved and autocatalysis of the PCSK9 zymogen occurs between Gln152 and Ser153 [valine-phenylalanine-alanine-glutamine (VFAQ) $152 /$ serine-isoleucine-proline (SIP)]. Mature PCSK9 (aa 153 to 692; roughly $60 \mathrm{kDa}$ ) undergoes a furin enzymatic inactivation, leading to a 55-kDa-truncated form. The orange boxed area represents the signal peptide (SP); the yellow boxed area represents the prodomain; the green boxed area represents the catalytic domain; and the blue boxed area represents the $\mathrm{C}$-terminal domain. 


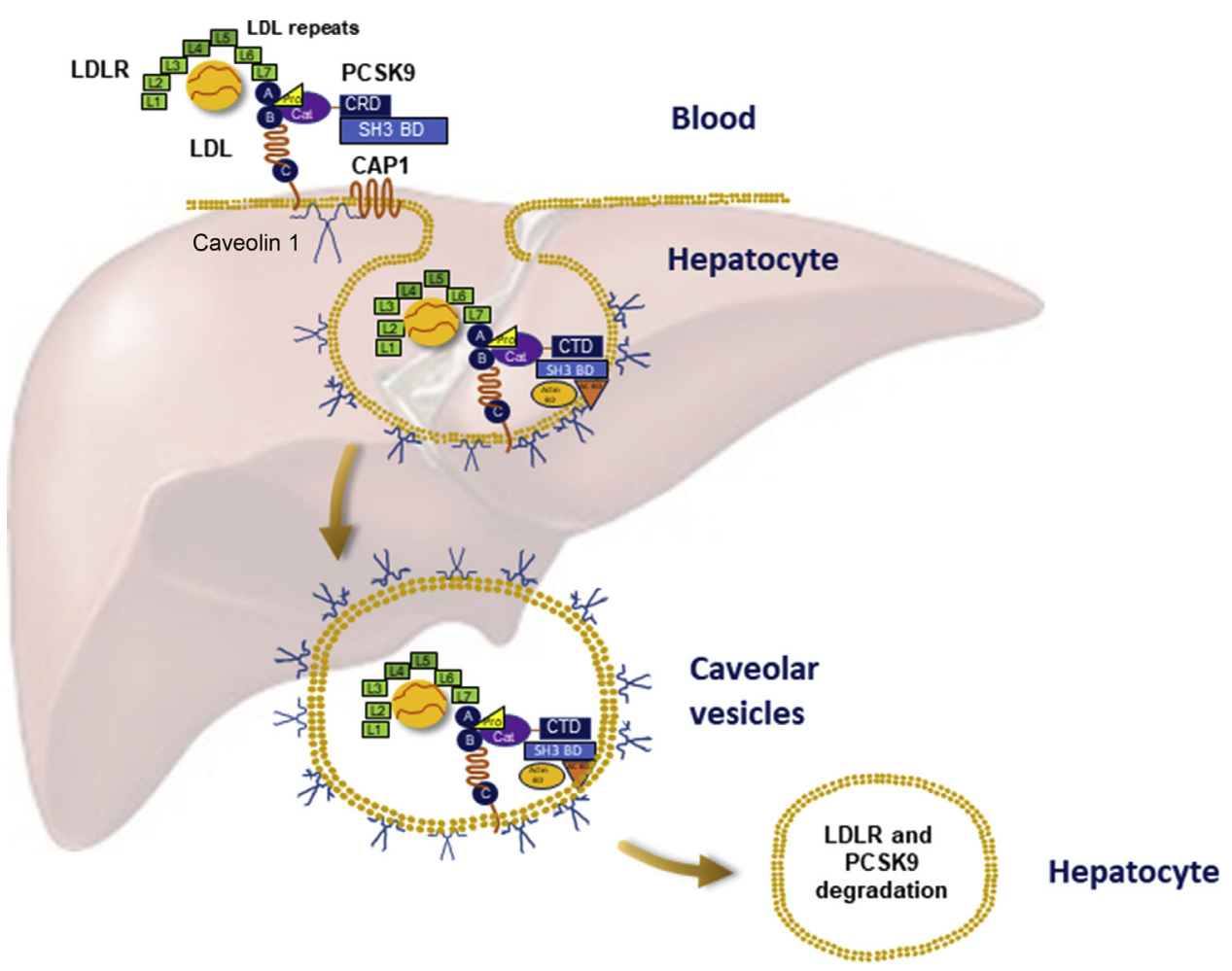

Figure 2 Cyclase-associated protein 1 (CAP1) has been described as a new binding partner of proprotein convertase subtilisin kexin type 9 (PCSK9). CAP1 contributes to mediate PCSK9-driven endocytosis and lysosomal degradation of low-density lipoprotein receptor (LDLR) through a process mediated by caveolae and not by clathrin. ${ }^{13} \mathrm{On}$ the cell surface at neutral $\mathrm{pH}$, the LDLR adopts an open extended conformation and binds to low-density lipoprotein (LDL) predominantly through the L4 and L5 domains of the LDL repeats. CTD, C-terminal domain; L, LDL repeats; SH3 BD, Src homology 3 binding domain.

without any involvement of proteasome or lysosomal cysteine proteases. ${ }^{15}$

Besides LDLR, PCSK9 promotes the degradation of other LDLR family members (eg, the very-low-density lipoprotein receptor (VLDLR)), although with a much lower efficiency. ${ }^{16}$ Kilodaltons $\left(\mathrm{K}_{\mathrm{d}}\right)$ for VLDLR and apolipoprotein $\mathrm{E}(\mathrm{apoE})$ receptor 2 are 379 and $516 \mathrm{nmol} / \mathrm{L}$, respectively. PCSK9 directly interacts with CD36, with a $\mathrm{K}_{\mathrm{d}}$ of $1.2 \mu \mathrm{mol} / \mathrm{L}$, and elicits its degradation through a lysosomal and proteasomal pathway. ${ }^{17}$ A proportion of circulating PCSK9 is bound to lipoproteins, LDL, high-density lipoprotein, or lipoprotein(a), although binding to lipoprotein(a) is not supported by in vitro data. ${ }^{18}$

Pulse-chase experiments show that PCSK9 is processed from the precursor form of $74 \mathrm{kDa}$ to the mature catalytic fragment of $62 \mathrm{kDa}$ in under 2 hours, and is ultimately secreted from the cells. ${ }^{19}$ This fragment can also undergo a second proteolytic cleavage mediated by the protease furin, which cleaves PCSK9 at the N-terminal region, after residue 218 , releasing an approximately $7-\mathrm{kDa}$ peptide and generating a PCSK9 residue of $55 \mathrm{kDa}$. The mature $(62-\mathrm{kDa})$ and furin-cleaved forms are both present in circulation. Overall, furin-cleaved PCSK9 is formed extracellularly, has a plasma clearance faster than the mature form, and once internalized, cannot get secreted back because of the lack of the prodomain, but retains a reduced efficiency to cause LDLR degradation. ${ }^{20}$
A precise mechanism for secretion is still lacking. The coat protein II adaptor protein SEC24A (part of an unknown sorting receptor complex) facilitates the ER-to-Golgi transport of PCSK9. Experiments in mice show that deficiency of SEC24A reduces the secretion of PCSK9, leading to a hypocholesterolemic phenotype. ${ }^{21}$ In this context, the C-terminal domain of PCSK9 might interact with a potential cargo receptor to mediate PCSK9 secretion, with SEC24A, SEC24B, and SEC24C, but not SEC24D, involved in endogenous secretion. ${ }^{22}$ This suggests a receptor-mediated mechanism for the recruitment of PCSK9 into coat protein II vesicles. The cargo receptor sorts soluble proteins into the coat protein II complex. In vitro studies in 293T cells show that a cargo receptor, surfeit locus protein 4 , facilitates secretion of PCSK9, ${ }^{23}$ an unconfirmed finding in cultured human hepatocytes (HEK293, Huh7, and HepG2 cell lines). ${ }^{24}$ Another hypothesis relies on the role of cytosolic dynamin-related protein 1. Primarily localized in mitochondria, dynamin-related protein 1 is associated with ER tubules in the liver and its inhibition promotes hepatic proteasomal degradation of PCSK9 in the early secretory pathway. Dynamin-related protein 1 inhibition raises the cytosolic localization of glucose-regulated protein 94, an ER chaperone that binds PCSK9 and prevents its interaction with LDLR in the ER. ${ }^{25}$ Finally, sortilin facilitates the transport of PCSK9 from the trans-Golgi network to plasma membranes. ${ }^{26}$ 


\section{Transcriptional Regulation of PCSK9}

PCSK 9 was identified as one of the 33 genes regulated by the sterol regulatory element binding protein (SREBP) family, as shown by a combined analysis of oligonucleotide microarray data from SREBP1a and SREBP2 transgenic mice and SREBP cleavage-activating protein knockout mice. ${ }^{27}$ Thus, identification of a sterol-regulatory element in the promoter region of PCSK9 explains its SREBP dependency and the reason why PCSK9 promoter activity is induced in response to cellular cholesterol depletion. ${ }^{28}$ The expression of PCSK9 is strongly dependent on a second transcription factor, the hepatocyte nuclear factor $1 \alpha$, whose binding site is in proximity ( $28 \mathrm{bp}$ upstream) to that of the sterol-regulatory element in the promoter region of PCSK9. ${ }^{29}$ It is worth mentioning that mammalian target of rapamycin complex 1 reduces the expression of PCSK9 by activating protein kinase $\mathrm{C} \delta$ and reducing hepatocyte nuclear factor $4 \alpha$ and hepatocyte nuclear factor $1 .{ }^{30}$ Finally, the carbohydrate-responsive element-binding protein, a critical glucose-sensing factor that regulates gene transcription in glycolysis and de novo lipogenesis, has been identified as a novel transcriptional factor of human PCSK9. ${ }^{31}$ This puts forth new mechanisms explaining how controlling intrahepatic glucose could be a therapeutic strategy to reduce cardiovascular $(\mathrm{CV})$ risk in type 2 diabetes.

\section{PCSK9 and Brain}

Even though the central nervous system accounts for $2.1 \%$ of body weight, it contains $23 \%$ of the sterol present in the whole-body pool. Considering that there is no detectable uptake of cholesterol carried by lipoproteins across the blood-brain barrier, high rates of de novo cholesterol synthesis in the glia and neurons provide the necessary sterols for early brain development. ${ }^{32}$ Although PCSK9 was first identified in the brain, its exact role in the central nervous system still needs to be clarified. In vitro and in vivo studies suggest that PCSK9 (NARC-1) is involved in the following: i) differentiation of neural progenitor cells to neurons, ii) regulation of neuronal apoptosis, and iii) activation of astrocytes and microglia, all facilitating PCSK9 expression in the cerebellum of adult humans. ${ }^{33}$

In zebrafish, PCSK9 is expressed in areas of continued neurogenesis, such as cortical, intracranial, and cerebellar granule neurons. ${ }^{34}$ In the mouse brain, PCSK9 is expressed in the telencephalon at the embryonic stage 12.5 , in the cerebellum from embryonic stage 17.7 to postnatal day 7 , and in adults, in the rostral extension of the olfactory peduncle. ${ }^{5}$ PCSK9 regulates expression of the LDLR in the same brain areas during development and not in adulthood without affecting brain morphology, cell differentiation, or synapses. ${ }^{35}$ It is worth mentioning that $L d l r^{-/-}$mice exhibit impaired learning and memory, ${ }^{36}$ whereas overexpression of the LDLR in brain markedly inhibits amyloid deposition and increases extracellular $\alpha \beta$ clearance. ${ }^{37}$

Alterations of cholesterol homeostasis associate with various neurodegenerative disorders, including Alzheimer disease. Specifically, cholesterol produced by astrocytes undergoes efflux to apoE-containing particles to be delivered to neurons by binding to specific receptors such as the LDLR, LDL receptor-related protein 1 (LRP1), VLDLR, and apoE receptor 2. These receptors, implicated in Alzheimer disease pathology, are degraded by PCSK9. apoE, mainly produced in and secreted from astrocytes in the brain, is lipidated by the ATP-binding cassette transporter A1 to supply cholesterol/lipids to neurons and other cells through LRP1 and CD36. PCSK9 down-regulates the protein expression of ATP-binding cassette transporter A1, thus leading to a possible modulation of the release of apoEcontaining lipoproteins. apoE isoforms may affect LRP1mediated $A \beta$ metabolism by directly interacting with $A \beta$ or competing with $\mathrm{A} \beta$ for receptor binding ${ }^{38}$ (Figure 3).

When overexpressed in $\mathrm{CHO}$ and human neuroglioma (H4) cells, PCSK9 reduces the expression of membrane protein $\beta$-site amyloid precursor protein-cleaving enzyme 1 (BACE1) ${ }^{39}$ responsible for the cleavage of amyloid precursor protein into the toxic amyloid $\beta$. This was confirmed in $P \operatorname{csk} 9^{-/-}$mice expressing low levels of BACE1 in the neocortex. ${ }^{39}$ However, there is no confirmation of the involvement of PCSK9 in the degradation of LDLR and BACE1 in the adult mouse brain. ${ }^{40}$ PCSK9 does not regulate either BACE1 levels or the predominant amyloidogenic fragment $A \beta_{42}$, released after BACE1 and $\gamma$-secretase activity.

Although a mendelian randomization analysis reported that the inhibition of PCSK9 might predispose individuals to Alzheimer disease, a clear mechanism and the consequent causality have not been confirmed. ${ }^{41}$ Conversely, negative conclusions were reported in the Reasons for Geographic and Racial Differences in Stroke (REGARDS) study, in which carriers of PCSK9 LOF variant C697X or Y142X did not show any change in neurocognitive performance, unlike in the case of carriers of the PCSK 9 R46L variant. ${ }^{38}$ Interestingly, considering that $A P O E 4$ is the major genetic risk factor for late-onset Alzheimer disease, ${ }^{42}$ increased levels of PCSK9 in APOE $\varepsilon 4$ carriers have been found. ${ }^{43}$

Because drug therapies targeting PCSK9 (both monoclonal antibodies and silencing RNA) reduce LDL cholesterol by $>50 \%$, understanding its role in cognitive impairment is important. Although genetic studies ${ }^{44}$ and major clinical trials did not find any impact on cognitive performance, ${ }^{45}$ data from the EudraVigilance database reported that administration of PCSK9 monoclonal antibodies is associated with a higher probability of nervous and psychiatric adverse drug reactions. ${ }^{46}$ Another important aspect is the link between PCSK9 and depressive mood. As reported in a retrospective study, depression increases PCSK9 levels, ${ }^{47}$ although a mutual effect cannot be excluded. Among 479,522 individuals of the UK Biobank, the ones 


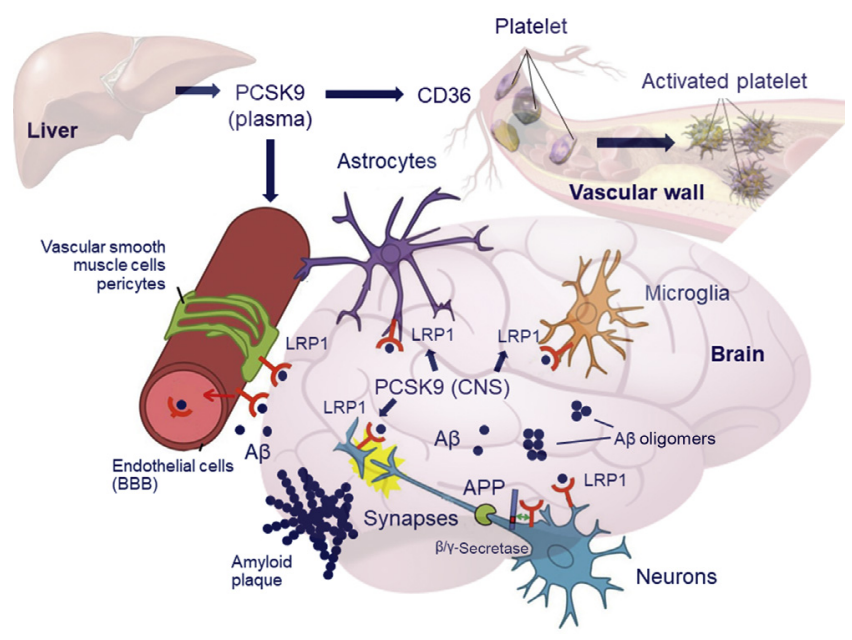

Figure 3 Role of proprotein convertase subtilisin kexin type 9 (PCSK9) on $A \beta$ amyloid deposition in central nervous system (CNS) and on platelet activation. Once released from the liver into the bloodstream, PCSK9 contributes to platelet activation by interacting with the CD36 receptor. PCSK9 is also present in the cerebrospinal fluid, and emerging evidence suggests its role in $A \beta$ deposition, potentially through modulation of lowdensity lipoprotein receptor-related protein 1 (LRP1) receptor. Considering that under physiological conditions, plasma PCSK9 does not cross the blood-brain barrier (BBB), PCSK9 in the central nervous system should be synthesized locally by neurons. APP, amyloid precursor protein.

carrying the LDL-lowering T allele rs 1159147 variant had a concomitant higher risk of depression. ${ }^{48}$ Although genetic analyses found a positive association between increased risk of depressive mood and circulating levels of PCSK9, the notion that lipid-lowering drugs might increase the risk of depression has not been confirmed in trials with PCSK9 inhibitors. $^{33}$

\section{PCSK9 and the Inflammatory Burden of Atherosclerosis}

Atherosclerosis is characterized by the retention of modified lipoproteins in the arterial wall, a burden initiated by the intramural retention of atherogenic lipoproteins, activating resident macrophages and recruitment of monocyte-derived cells. However, native LDL can be taken up by macrophages by macropinocytosis, especially when LDL is elevated. ${ }^{49}$

Compelling evidence implicates PCSK9 in plaque development. It is expressed in endothelial cells, vascular smooth muscle cells, and macrophages. In macrophages, there is a stepwise increase in PCSK9 gene expression while transitioning from monocytes (PCSK9 being almost undetectable), to differentiating monocytes (significantly up-regulated), to fully differentiated macrophages. ${ }^{50}$ In vascular smooth muscle cells, PCSK9 expression is instead regulated in response to reactive oxygen species ${ }^{51}$ and shear stress. ${ }^{52}$ Experiments aimed at investigating the impact of different blood flow patterns on PCSK9 expression showed that low-flow state at arterial branch points increased PCSK9 (both gene and protein) compared with normal flow, whereas laminar flow (preventing the accumulation of atherogenic lipids) reduced PCSK $9 .{ }^{53}$ Interestingly, PCSK9 inhibition by evolocumab (a monoclonal antibody) rapidly reversed coronary artery endothelial dysfunction in $\mathrm{HIV}^{+}$individuals and people with dyslipidemia. $^{54}$

The hypothesis that PCSK9 might mediate inflammation in atherogenesis comes from the seminal article by Giunzioni et al, ${ }^{55}$ demonstrating that human PCSK9 alters plaque morphology, increasing infiltration of inflammatory bone marrow-derived Ly6C ${ }^{\text {high }}$ monocytes into the lesion, leading to their differentiation into macrophages, a process entirely dependent on the LDLR. In line with these findings, expression of human PCSK9 in lipopolysaccharidestimulated murine peritoneal macrophages increases mRNA expression of tumor necrosis factor (TNF)- $\alpha$ and IL$1 \beta$, as later confirmed in human primary macrophages. ${ }^{56}$ Exposure to human recombinant PCSK9 up-regulates the mRNA expression of proinflammatory cytokines and chemokines (eg, IL-1 $\beta$, IL-6, TNF- $\alpha$, CXCL2, and monocyte chemoattractant protein-1). Accordingly, atherosclerotic lesions of mice injected with short hairpin RNA (shRNA) for PCSK9 have fewer macrophages, and a reduced mRNA expression of vascular inflammatory regulators such as TNF- $\alpha$, IL-1 $\beta$, monocyte chemoattractant protein-1, toll-like

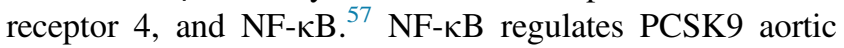
expression through the toll-like receptor 4-MyD88 pathway but not toll-like receptor $4-$ TRIF. $^{53}$

Interestingly, in an atherosclerosis-prone mouse model, Pcsk9 deletion led to a phenotype with fewer atherogenic lipoproteins, via mechanisms independent of the LDLR. Compared with mice lacking $L d l r$ and Apobec1, endothelial cells exposed to lipoproteins from animals simultaneously lacking Ldlr, Apobecl, and Pcsk9 expressed fewer adhesion molecules (Icam-1), inflammatory cytokines (IL-1 $\beta)$, and chemotactic factors [eg, Ccl2 (Mcp-1) and Ccl-7 (Mcp-3)], all promoting monocyte adhesion and infiltration into the vessel wall. $^{58}$

Among the plethora of inflammatory mediators and scavenger receptors implicated in the inflammatory burden of atherosclerosis, lectin-like oxidized lipoprotein-1 (LOX1) plays a prominent role. In arterial tissues, cultured endothelial cells, and vascular smooth muscle cells, mitochondrial reactive oxygen species generation exacerbates a positive cross talk between PCSK9 and LOX-1, in which LOX-1 increases PCSK9 and PCSK9 promotes LOX-1 and oxidized LDL uptake. ${ }^{51}$ Moreover, in TNF- $\alpha$-primed macrophages, treatment with exogenous murine PCSK9 upregulates expression of scavenger receptors (the class A macrophage scavenger receptor, CD36, and LOX-1) and enhances oxidized LDL uptake. ${ }^{59}$

Internalization of lipids into macrophages is also facilitated by the LDLR-related protein family of receptors (eg, LRP5). ${ }^{50}$ Although PCSK9 and LRP5 do not affect each other's expression, LRP5 and PCSK9 interact directly, 
being colocalized at the perinuclear area. Immunoprecipitation experiments have shown that exposure to aggregated LDL favors the formation of a complex in the cytoplasm of macrophages, which is stronger in lipid-loaded macrophages. Silencing of LRP5 results in a reduction in PCSK9 release. $^{50}$

As previously reviewed, accumulation of lipoproteinderived lipids in macrophages or dendritic cells induces activation of a multiprotein complex termed inflammasome. ${ }^{60}$ Human atherosclerotic lesions show increased expression of the major components of the NOD-, LRR- and pyrin domain-containing protein (NLRP3) inflammasome, characterized by three domains: a C-terminal lysine-rich domain, a central nucleotide domain (the NACHT domain), and a terminal pyrin domain. Formation of the NLRP3 complex induces autocleavage and activation of caspase $1{ }^{61}$ In the intertwined relationship between PCSK9 and inflammation, ${ }^{62}$ interferon- $\gamma$ increases mRNA expression of PCSK9 ${ }^{63}$; NLRP3 and its downstream signals caspase-1, IL-18, and IL-1 $\beta$ all participate in PCSK9 secretion. ${ }^{64}$

Vascular inflammation, T-cell accumulation in aortic plaques, and necrotic core formation are attenuated by treatment with the PCSK9 monoclonal antibody alirocumab $^{65}$ or an anti-PCSK9 vaccine. ${ }^{66,67}$ Immunization with the AT04A vaccine, recognizing the PCSK9 epitope (amino acids 153 to 692), reduces the number of monocytes adhering to the activated endothelium, as well as the expression of intercellular adhesion molecule 1 and NLRP3 in macrophages. ${ }^{66}$ A similar pattern was is found when the PCSK9Q $\beta-003$ vaccine was tested in $a p o E^{-1-}$ mice. $^{67}$

\section{PCSK9 Regulates TG-Rich Lipoproteins}

Relative to the so-called CV residual risk, epidemiologic and genetic studies have reported a causal role for triglyceride (TG)-rich lipoproteins. Carriers of the GOF S127R variant show a lipid profile characterized by a dramatic increase in the production rate of apoB100 (threefold), VLDL (threefold), and intermediate-density lipoprotein (threefold) compared with matched control subjects or carriers of LDLR mutations. ${ }^{68}$ One of the leading hypotheses relies on the ability of PCSK9 to promote apoB (and VLDL) secretion by protecting apoB from LDLR-induced intracellular catabolism. ${ }^{69} \mathrm{~A}$ direct involvement of the LDLR in the PCSK9-driven apoB secretion is supported by experiments in a mouse model overexpressing PCSK9. ${ }^{70}$ A 24-hour fasting leads to a 2.5 -fold increment in plasma TG levels, with a sharp increase in the apoB 100 and apoB48 content of VLDL, intermediate-density lipoprotein, and LDL. These increases do not involve changes in lipase activity, but rather correspond to a faster catabolism: the fractional catabolic rate of VLDL/intermediate-density lipoprotein apoB is maximal in fasted mice overexpressing PCSK9. To disentangle the role of LDLR in this process, PCSK9 was overexpressed in a background of $\mathrm{Ldlr}^{-/-}$mouse model. On fasting, both genotypes showed hypertriglyceridemia, highlighting that the modulation of LDLR is required for the VLDL output. ${ }^{70}$

Concerning the LDLR-independent pathway, Sun et $\mathrm{al}^{71}$ found that overexpression of PCSK9 in livers of C57BL/ 6, $\mathrm{Ldlr}^{-/-}$, or $\mathrm{Ldlr}^{-/}{ }^{-}$Apobec $\mathrm{I}^{-/-}$mice (models for human hyperlipidemia), led to an increase in plasma VLDL, LDL apoB100, and apoB48. ${ }^{71}$ PCSK9 interacts with apoB to prevent/inhibit/decrease the mobilization of apoB toward autophagosomes for degradation via the autophagosome/ lysosome pathway. Finally, a mechanism of action outside of the lack of LDLR activity ${ }^{72}$ involves overexpression of PCSK9 GOF D374Y in mice leading to a phenotype with a large increase in TG-rich lipoproteins compared with wildtype or $\mathrm{Ldlr}^{-/-}$mice.

\section{Role of PCSK9 in Platelet Activation}

Platelet aggregation and activation of the coagulation cascade are common etiologies of arterial and venous thrombotic events. Thrombosis in the arterial circulation is the main cause of acute coronary syndromes and ischemic stroke. ${ }^{73}$ PCSK9 levels increase after acute coronary syndrome ${ }^{74}$ and are positively associated with severity of coronary artery lesions. ${ }^{75}$ The results of the Association of PCSK9 Serum levels and Platelet Reactivity in Patients with Acute Coronary Syndrome Treated with Prasugrel or Ticagrelor (PCSK9-REACT) study are in line with this evidence and show a positive association between circulating PCSK9 and platelet reactivity in acute coronary syndrome patients undergoing percutaneous coronary intervention. ${ }^{76}$

The possible link between PCSK9 and platelet activation was first explored in $P c s k 9^{-/-}$mice, showing a reduced formation and stability of arterial thrombus. ${ }^{77}$ These findings indicate that the $P c s k 9^{-/}$mouse model develops smaller venous thrombi after ligation of the inferior vena cava with reduced P-selectin levels. ${ }^{78}$ An improved understanding of the mechanisms explaining the impact of PCSK9 on platelet activation and thrombosis came from Qi et $\mathrm{al}^{79}$ (Figure 3). They used pharmacologic, immunologic, and genetic approaches to show that enhanced platelet responsiveness, arterial thrombosis, and myocardial infarction expansion after myocardial infarction driven by PCSK9 are dependent on platelet CD36 expression and signaling. ${ }^{79}$ Platelet activation and in vivo thrombosis were antagonized by both evolocumab and aspirin. Furthermore, this study was the first one supporting PCSK9 as a CD36 ligand, similar to oxidized LDL, advanced glycated proteins, and cell-derived microvesicles. ${ }^{79}$

\section{PCSK9 and Intestine}

Early studies identified Pcsk9 mRNA expression substantially in the small intestine in mice and in the human 
colon carcinoma cell line LoVo-C5. Subsequently, Pcsk9 was shown to express homogeneously along the intestinal cephalon-caudal axis in the mouse, whereas immunohistochemical analysis of jejunal and ileal biopsies showed that PCSK9 was present in enterocytes and goblet cells. ${ }^{80}$

After intracellular re-esterification, long-chain fatty acids and cholesterol esters are associated with phospholipids and apolipoproteins (eg, apoB48) to produce TGrich lipoproteins. The lack of PCSK9 leads to a reduction in postprandial lipemia, caused partially by an increased hepatic clearance of chylomicrons and their remnants without changes in gastric emptying and intestinal transit. ${ }^{81}$ Studies using the first intestine-specific PCSK9deficient $\left(i-P \operatorname{csk} 9^{-/-}\right)$mouse model ${ }^{82}$ show that liverderived PCSK9, and not the intracellular intestinal form, through its canonical regulation on LDLR expression, is the key regulator of postprandial lipemia. Indeed, administration of a specific monoclonal antibody (alirocumab) did not reduce postprandial lipemia in $\mathrm{Ldlr}^{-1-}$ mice. $^{82}$ These findings are in line with the impact of evolocumab on postprandial lipemia [namely, TG $(-21 \%)$, apoB48 $(-17 \%)$, and $\mathrm{VLDL}_{1}(-15 \%)$ in patients with type 2 diabetes mellitus or carriers of PCSK9 LOF mutations]. ${ }^{83}$

Studies in $\mathrm{CaCo} 2$ cells show that recombinant PCSK9 directly stimulates, by roughly $50 \%$, the intestinal production of TG-rich lipoproteins, apoB48, and apoB100, as well as that of fatty acid synthase (FAS), stearoyl-CoA desaturase $(S C D)$, and diacylglycerol O-acyltransferase (DGAT) $2 .{ }^{84}$ In human PCSK9 (hPCSK9) transgenic mice overexpressing human PCSK9 at the physiological levels, LDLR levels in the small intestine were reduced by 54\% compared with $P c s k 9^{-/}$or wild-type models, whereas the absence of mouse PCSK9 (mPCSK9) increased LDLR levels by nearly $70 \%$. Moreover, hPCSK9 transgenic mice has increased intestinal microsomal triglyceride transfer protein levels and activity regardless of LDLR expression, whereas the absence of mPCSK9 does not alter microsomal triglyceride transfer protein at any level, mRNA, protein, or activity. ${ }^{84}$ However, in $i$-Pcsk $9^{-/-}$mice, no significant changes were found in the mRNA expression of Mtp and other lipogenic genes in the small intestine compared with control mice. ${ }^{82}$

Experiments in Caco-2/15 cells show that PCSK9 increases the expression of Niemann-Pick C1 like 1, a key protein in cholesterol absorption. However, this effect is consequent only to a reduced LDL uptake and a decrement in cholesterol pool inside the cell, as a result of the PCSK9driven degradation of LDLR at the basolateral membrane of the enterocytes. ${ }^{85}$

In addition to its effect on postprandial lipemia, PCSK9 acts as a modulator of transintestinal cholesterol excretion, an alternative route for plasma cholesterol excretion. Transintestinal cholesterol excretion is increased in $P c s k 9^{-/-}$ mice and rapidly reduced when PCSK9 is replaced by i.v. injection. The effect on transintestinal cholesterol excretion seems fully dependent on LDLR function because it is lost in $\mathrm{Ldlr}^{-1-}$ mice. $^{86}$

\section{PCSK9 and Pancreas}

In pancreatic $\beta$ cells, the accumulation of cholesterol occurs mainly via LDLR. Any genetic or pharmacologic intervention that increases LDLR expression is virtually associated with cholesterol overload in $\beta$ cells, a process dampening glucose-stimulated insulin secretion.

The first evidence of the expression of PCSK9 in the pancreas came from in vitro experiments on RIN-m5F and bTC-3 $\beta$ cells and MIN6 pancreatic islet cells. ${ }^{5,87}$ Later studies in in vivo murine models show that PCSK9 mRNA is expressed in isolated pancreatic islets and colocalizes with somatostatin in human pancreatic $\delta$ cells. While PCSK9 is detectable in $\alpha$ cells, $\beta$ cells, or in the exocrine tissue, LDLR expression is significantly increased in the $\beta$ cells of the Pcsk $9^{-1-}$ mice. ${ }^{88}$ Ex vivo experiments demonstrate that recombinant PCSK9 reduces the expression of LDLR in the pancreatic islets, whereas those isolated from $P s c k 9^{-1-}$ mice show a significant increase in the LDLR content (200\%). Similarly, Mbikay et al ${ }^{87}$ found a higher content of LDLR in the whole pancreas of $P c s k 9^{-/-}$mice compared with wild type. These effects were mostly mediated in an endocrine rather than in an autocrine manner. ${ }^{88}$

Relative to glucose homeostasis, 4-month-old male $P c s k 9^{-1-}$ mice exhibit impaired glucose tolerance with an altered glucose-stimulated insulin secretion. ${ }^{87}$ The lack of PCSK9 leads to significantly higher fasting glucose, with reduced pancreatic and fasting plasma insulin. Downregulation of levels of $\mathrm{PC} 1 / 3$ proteins involved in insulin biosynthesis is observed in $P \operatorname{csk} 9^{-/}$mice fed a Western diet. ${ }^{87}$ In line with these findings, the absence of PCSK9 in mice fed a standard or a high-fat diet is associated with an impaired glucose tolerance. Despite a normal insulin sensitivity, plasma insulin and C-peptide levels are significantly reduced, and the pancreatic insulin content is increased. These data suggest a defective insulin secretion, a feature confirmed in PCSK9 R46L carriers, who present a lower homeostasis model assessment of $\beta$-cell function, indicating an impaired $\beta$-cell functionality. ${ }^{89}$ In pancreatic islets, the increased expression of LDLR is associated with PCSK9 deficiency and paralleled by an accumulation of cholesterol esters with a down-regulation of genes involved in cholesterol biosynthesis and uptake. Herein, the role of LDLR, the main target of PCSK9, is crucial. It is responsible for the phenotype, because the knockdown of both LDLR and PCSK9 completely revert the metabolic and pancreatic derangements seen in the $P c s k 9^{-/-}$mouse model. Further evidence comes from the analysis of liver from the $P c s k 9^{-/-}$mouse model that unveils the marginal role of circulating PCSK9 on glucose metabolism and $\beta$-cell function. ${ }^{89}$ Pancreatic islet morphology indicates PCSK9 deficiency leading to alterations associated with signs of 
inflammation and early apoptosis. ${ }^{87,89}$ In particular, the Western diet significantly increases both islet mass and numbers in $P c s k 9^{-1-}$ mice, also showing larger and possibly immature secretory granules, suggesting an abnormal biogenesis of insulin secretory granules. ${ }^{90}$ Finally, different conclusions have been reached by using human pancreatic sections and EndoC- $\beta \mathrm{H} 1$ cells or $\beta$-cell-specific Pcsk $9^{-/-}$ KO mice. Inhibition of exogenous or endogenous PCSK9 did not affect insulin secretion and specific PCSK9 deletion in $\beta$-cells did not led to any toxic effect. ${ }^{91,92}$

\section{PCSK9 and Adipose Tissue}

Human adipose tissue is among the numerous tissues that express PCSK9. ${ }^{93}$ A significant accumulation of visceral adipose tissue is found in $P \operatorname{csk} 9^{-/-}$mice ${ }^{90}$ fed a Western diet. In female mice, this diet leads to an increase in perigonadal white adipose tissue. ${ }^{90}$ Similarly, carriers of the $R 46 L$ LOF variant show an increased ectopic fat accumulation. ${ }^{94}$

The deletion of PCSK9 leads to adipocyte hypertrophy, independent of the presence of LDLR, with a higher fatty acid uptake and an increase in TG synthesis in perigonadal and inguinal pads. Furthermore, circulating PCSK9 downregulates the expression of the surface VLDLR, especially in females, as confirmed by higher protein levels of this receptor in perigonadal depots of $P c s k 9^{-1-}$ mice. Interestingly, this effect does not implicate LDLR involvement. ${ }^{95}$ Further analysis shows interaction and colocalization of PCSK9 with the endogenous CD36 at the adipocyte cell surface as well as in lysosomes. Indeed, PCSK9 directly interactes with CD36, inducing degradation through a mechanism involving both lysosomes and proteasome, with a consequent reduced uptake of CD36 ligands. ${ }^{17}$ CD36 protein levels are up-regulated in the visceral adipose tissue of $P \operatorname{csk} 9^{-1-}$ mice. ${ }^{95}$

Clinical studies also corroborate these findings by the characterization of subjects with low circulating PCSK9 levels. Their white adipose tissue depots present a reduced function, as assessed by the lower lipoprotein lipase activity and high surface expression of LDLR and CD36, with increased NLRP3 inflammasome activation. ${ }^{96}$ As to possible mechanisms regulating PCSK9 expression, insulin treatment increases PCSK9 expression in human adipocytes, an effect partially counteracted by the atrial natriuretic peptide. Interestingly, incubation of human adipocytes with LDL isolated from human plasma lead to an initial increase of intracellular PCSK9 levels, together with an increment of $L D L R$, SREBP-1c, and SREBP-2 expression. In the following 18 hours, increase in the secreted mature form of PCSK9 is associated with a reduced LDLR expression, suggesting that PCSK9 in adipocytes are fully functional. In support of this hypothesis, the decrement in PCSK9 expression on atrial natriuretic peptide treatment is paralleled by reduced LDLR degradation. ${ }^{93}$
Among the different white adipose tissue loci, the visceral epicardial adipose tissue may play an important role in the pathogenesis of $\mathrm{CV}$ disease. In patients with coronary artery or valvular diseases, PCSK9 was positively correlated with epicardial adipose tissue thickness and inflammation. ${ }^{97} \mathrm{~A}$ positive association was also found between PCSK9 and several local proinflammatory mediators such as chemokines, chemokine receptors, ILs, and cytokines. ${ }^{97}$ In line with this finding, PCSK9 GOF Ossabaw mini-pigs showed an up-regulated pericardial fat mRNA expression of TNF$\alpha{ }^{98}$ However, the PCSK9 content in epicardial adipose tissue was not associated with plasma PCSK9 concentrations, suggesting that epicardial adipose tissue inflammation could be associated with the local PCSK9 levels, rather than with the circulating ones. ${ }^{97}$

Finally, considering the link between adipose tissue and $\mathrm{CV}$ health, ${ }^{99}$ it is worth mentioning that adiponectin, leptin, and resistin regulate PCSK9 expression. In wild-type and apo $E^{-/-}$mice, adiponectin have an opposite effect by increasing and reducing PCSK9 expression, respectively, through the involvement of peroxisome proliferatoractivated receptor $\gamma$ and AMP-activated protein kinase $\alpha$. This opposing behavior may be explained by a specific interaction between PCSK9 and apoE. ${ }^{100}$ Relative to leptin, in HepG2 cells, this adipokine increases PCSK9, an effect that depends on the STAT3 pathway, ${ }^{101}$ whereas in leptindeficient ob/ob mice, the effects of leptin on PCSK9 are strongly modified by sexual hormones. ${ }^{102}$ Finally, resistin increases PCSK9 mRNA and protein expressions, possibly through the up-regulation of $S R E B P-2$ or a posttranscriptional stabilization process. ${ }^{103}$

\section{PCSK9 and Tumors}

Preclinical and clinical studies have shown that manipulating cholesterol metabolism inhibits tumor growth, reshapes the immunologic landscape, and reinvigorates anti-tumor immunity. ${ }^{104}$ The evidence describing the involvement of PCSK9 in cell proliferation and apoptosis raises the question of whether this protein is involved in cancer risk. Although a partial hepatectomy increases the expression of PCSK9 in mice, the same procedure leads to an impaired hepatocyte proliferation and enhanced apoptosis in $P \operatorname{csk} 9^{-1-}$ mice. ${ }^{3}$ Carriers of LOF variants showe a reduced incidence of breast cancer, whereas those carrying GOF variants have an increased risk. ${ }^{105}$ Inoculation of nanoliposomal anti-PCSK9 vaccine in mice bearing breast or colorectal cancers results in a moderate reduction in tumor growth and an increase in lifespan. ${ }^{106,107}$ In an in vitro model of human lung adenocarcinoma A549 cells, PCSK9 silencing exhibits anti-tumor activity by inducing apoptosis. ${ }^{108}$ Finally, in the context of immune therapy and cancer, many efforts are underway to improve the effectiveness of immune checkpoint therapy. Inhibition of PCSK9 can boost the response of tumors to immune checkpoint therapy in a cholesterol-independent 
manner. The reduction of PCSK9 by genetic or pharmacologic approaches has the ability to increase the expression of major histocompatibility protein class I presentation on tumor cell surfaces, thus favoring entry of $\mathrm{CD} 8^{+} \mathrm{T}$ lymphocytes and reducing tumor growth. ${ }^{109}$

\section{Future Perspectives and Conclusions}

Although there is a huge escalation of experimental and clinical data describing PCSK9 pathophysiology and possible effects besides lipid lowering, other effects such as the case of calcific aortic valve stenosis and the regulation of the hypothalamic-pituitary-gonadal axis need to be explored further. Although calcific aortic valve stenosis is a condition conferring an increased risk of major cardiac events, far less is known about PCSK9 and calcific aortic valve stenosis. Carriers of PCSK9 R46L LOF variant compared with noncarriers have a reduced prevalence of this disease (odds ratio, 0.80; 95\% CI, 0.70-0.91). ${ }^{110}$ Relative to sex hormones, administration of estradiol in ovariectomized $a p o E^{-/-}$mice (a model developing aortic atherosclerosis) increases plasma PCSK9 and hepatic mRNA expression versus specific controls. ${ }^{11}$ In HepG2 cells, estradiol, by binding to a specific estrogen-responsive element, increases PCSK9 activity in a dose-dependent manner. ${ }^{111}$

Overall, unveiling noncholesterol pathways related to PCSK9 is the key to understanding long-term PCSK9 pharmacologic inhibition. PCSK9 inhibition may increase the risk of new-onset diabetes but can also provide a large CV benefit driven by LDL lowering. The possibility of categorizing PCSK9 among danger-associated molecular patterns needs to be explored further. This broad family of modified endogenous structures, generated during inflammation, tissue injury, and oxidant stress, interacts with specific scavenger receptors and toll-like receptors to trigger proinflammatory and prothrombotic responses by the innate immune system. ${ }^{112}$ These findings suggest PCSK9 inhibition as a potentially safe therapeutic target to prevent arterial thrombosis in individuals with elevated PCSK9 levels. Identification of new PCSK9 signaling pathways may constitute a significant challenge for molecular biology, specially considering that PCSK9 is a mediator of many metabolic processes. Finally, involvement in immune checkpoint therapy for cancer provides a compelling rationale to conduct future clinical trials in patients with cancer by combining checkpoint inhibitor anticancer drugs with inhibitors of PCSK9.

\section{References}

1. Abifadel M, Varret M, Rabes JP, Allard D, Ouguerram K, Devillers M, Cruaud C, Benjannet S, Wickham L, Erlich D, Derre A, Villeger L, Farnier M, Beucler I, Bruckert E, Chambaz J, Chanu B, Lecerf JM, Luc G, Moulin P, Weissenbach J, Prat A, Krempf M,
Junien C, Seidah NG, Boileau C: Mutations in PCSK9 cause autosomal dominant hypercholesterolemia. Nat Genet 2003, 34:154-156

2. Cohen JC, Boerwinkle E, Mosley TH Jr, Hobbs HH: Sequence variations in PCSK9, low LDL, and protection against coronary heart disease. N Engl J Med 2006, 354:1264-1272

3. Zaid A, Roubtsova A, Essalmani R, Marcinkiewicz J, Chamberland A, Hamelin J, Tremblay M, Jacques H, Jin W, Davignon J, Seidah NG, Prat A: Proprotein convertase subtilisin/kexin type 9 (PCSK9): hepatocyte-specific low-density lipoprotein receptor degradation and critical role in mouse liver regeneration. Hepatology 2008, 48:646-654

4. Dijk W, Cariou B: Efficacy and safety of proprotein convertase subtilisin/kexin 9 inhibitors in people with diabetes and dyslipidaemia. Diabetes Obes Metab 2019, 21 Suppl 1:39-51

5. Seidah NG, Benjannet S, Wickham L, Marcinkiewicz J, Jasmin SB, Stifani S, Basak A, Prat A, Chretien M: The secretory proprotein convertase neural apoptosis-regulated convertase 1 (NARC-1): liver regeneration and neuronal differentiation. Proc Natl Acad Sci U S A 2003, 100:928-933

6. Henrich S, Lindberg I, Bode W: Than ME: Proprotein convertase models based on the crystal structures of furin and kexin: explanation of their specificity. J Mol Biol 2005, 345:211-227

7. Cunningham D, Danley DE, Geoghegan KF, Griffor MC, Hawkins JL, Subashi TA, Varghese AH, Ammirati MJ, Culp JS, Hoth LR, Mansour MN, McGrath KM, Seddon AP, Shenolikar S, Stutzman-Engwall KJ, Warren LC, Xia D, Qiu X: Structural and biophysical studies of PCSK9 and its mutants linked to familial hypercholesterolemia. Nat Struct Mol Biol 2007, 14:413-419

8. Naureckiene S, Ma L, Sreekumar K, Purandare U, Lo CF, Huang Y, Chiang LW, Grenier JM, Ozenberger BA, Jacobsen JS, Kennedy JD, DiStefano PS, Wood A, Bingham B: Functional characterization of Narc 1, a novel proteinase related to proteinase K. Arch Biochem Biophys 2003, 420:55-67

9. Saavedra YG, Day R, Seidah NG: The M2 module of the Cys-Hisrich domain (CHRD) of PCSK9 protein is needed for the extracellular low-density lipoprotein receptor (LDLR) degradation pathway. J Biol Chem 2012, 287:43492-43501

10. Holla OL, Cameron J, Tveten K, Strom TB, Berge KE, Laerdahl JK, Leren TP: Role of the C-terminal domain of PCSK9 in degradation of the LDL receptors. J Lipid Res 2011, 52:1787-1794

11. Zhang DW, Lagace TA, Garuti R, Zhao Z, McDonald M, Horton JD, Cohen JC, Hobbs HH: Binding of proprotein convertase subtilisin/kexin type 9 to epidermal growth factor-like repeat A of low density lipoprotein receptor decreases receptor recycling and increases degradation. J Biol Chem 2007, 282:18602-18612

12. Poirier S, Mayer G, Poupon V, McPherson PS, Desjardins R, Ly K, Asselin MC, Day R, Duclos FJ, Witmer M, Parker R, Prat A, Seidah NG: Dissection of the endogenous cellular pathways of PCSK9-induced low density lipoprotein receptor degradation: evidence for an intracellular route. J Biol Chem 2009, 284: 28856-28864

13. Jang HD, Lee SE, Yang J, Lee HC, Shin D, Lee H, Lee J, Jin S, Kim S, Lee SJ, You J, Park HW, Nam KY, Lee SH, Park SW, Kim JS, Kim SY, Kwon YW, Kwak SH, Yang HM, Kim HS Cyclase-associated protein 1 is a binding partner of proprotein convertase subtilisin/kexin type- 9 and is required for the degradation of low-density lipoprotein receptors by proprotein convertase subtilisin/kexin type-9. Eur Heart J 2020, 41:239-252

14. Huang Y, Ning K, Li WW, Lin G, Hou CL, Wang MJ, Zhu YC: Hydrogen sulfide accumulates LDL receptor precursor via downregulating PCSK9 in HepG2 cells. Am J Physiol Cell Physiol 2020, 319:C1082-C1096

15. Maxwell KN, Fisher EA, Breslow JL: Overexpression of PCSK9 accelerates the degradation of the LDLR in a post-endoplasmic reticulum compartment. Proc Natl Acad Sci U S A 2005, 102: 2069-2074 
16. Gu HM, Adijiang A, Mah M, Zhang DW: Characterization of the role of EGF-A of low density lipoprotein receptor in PCSK9 binding. J Lipid Res 2013, 54:3345-3357

17. Demers A, Samami S, Lauzier B, Des Rosiers C, Ngo Sock, et alOng H, Mayer G: PCSK9 induces CD36 degradation and affects long-chain fatty acid uptake and triglyceride metabolism in adipocytes and in mouse liver. Arterioscler Thromb Vasc Biol 2015, 35:2517-2525

18. Ferri N, Corsini A, Macchi C, Magni P, Ruscica M: Proprotein convertase subtilisin kexin type 9 and high-density lipoprotein metabolism: experimental animal models and clinical evidence. Transl Res 2016, 173:19-29

19. Lagace TA, Curtis DE, Garuti R, McNutt MC, Park SW, Prather HB, Anderson NN, Ho YK, Hammer RE, Horton JD: Secreted PCSK9 decreases the number of LDL receptors in hepatocytes and in livers of parabiotic mice. J Clin Invest 2006, 116 : 2995-3005

20. Oleaga C, Hay J, Gurcan E, David LL, Mueller PA, Tavori H, Shapiro MD, Pamir N, Fazio S: Insights into the kinetics and dynamics of the furin-cleaved form of PCSK9. J Lipid Res 2020, 62: 100003

21. Chen XW, Wang H, Bajaj K, Zhang P, Meng ZX, Ma D, Bai Y, Liu HH, Adams E, Baines A, Yu G, Sartor MA, Zhang B, Yi Z, Lin J, Young SG, Schekman R, Ginsburg D: SEC24A deficiency lowers plasma cholesterol through reduced PCSK9 secretion. eLife 2013, 2: e00444

22. Deng SJ, Shen Y, Gu HM, Guo S, Wu SR, Zhang DW: The role of the C-terminal domain of PCSK9 and SEC24 isoforms in PCSK9 secretion. Biochim Biophys Acta Mol Cell Biol Lipids 2020, 1865: 158660

23. Emmer BT, Hesketh GG, Kotnik E, Tang VT, Lascuna PJ, Xiang J, Gingras AC, Chen XW, Ginsburg D: The cargo receptor SURF4 promotes the efficient cellular secretion of PCSK9. Elife 2018, 7: e38839

24. Shen Y, Wang B, Deng S, Zhai L, Gu HM, Alabi A, Xia X, Zhao Y, Chang X, Qin S, Zhang DW: Surf4 regulates expression of proprotein convertase subtilisin/kexin type 9 (PCSK9) but is not required for PCSK9 secretion in cultured human hepatocytes. Biochim Biophys Acta Mol Cell Biol Lipids 2020, 1865:158555

25. Rogers MA, Hutcheson JD, Okui T, Goettsch C, Singh SA, Halu A, Schlotter F, Higashi H, Wang L, Whelan MC, Mlynarchik AK, Daugherty A, Nomura M, Aikawa M, Aikawa E: Dynamin-related protein 1 inhibition reduces hepatic PCSK9 secretion. Cardiovasc Res 2021, [E-pub ahead of print] doi: 10.1093/cvr/cvab034

26. Gustafsen C, Kjolby M, Nyegaard M, Mattheisen M, Lundhede J, Buttenschon H, Mors O, Bentzon JF, Madsen P, Nykjaer A, Glerup S: The hypercholesterolemia-risk gene SORT1 facilitates PCSK9 secretion. Cell Metab 2014, 19:310-318

27. Horton JD, Shah NA, Warrington JA, Anderson NN, Park SW, Brown MS, Goldstein JL: Combined analysis of oligonucleotide microarray data from transgenic and knockout mice identifies direct SREBP target genes. Proc Natl Acad Sci U S A 2003, 100: 12027-12032

28. Jeong HJ, Lee HS, Kim KS, Kim YK, Yoon D, Park SW: Steroldependent regulation of proprotein convertase subtilisin/kexin type 9 expression by sterol-regulatory element binding protein-2. J Lipid Res 2008, 49:399-409

29. Dong B, Wu M, Li H, Kraemer FB, Adeli K, Seidah NG, Park SW, Liu J: Strong induction of PCSK9 gene expression through HNF1alpha and SREBP2: mechanism for the resistance to LDLcholesterol lowering effect of statins in dyslipidemic hamsters. J Lipid Res 2010, 51:1486-1495

30. Ai D, Chen C, Han S, Ganda A, Murphy AJ, Haeusler R, Thorp E, Accili D, Horton JD, Tall AR: Regulation of hepatic LDL receptors by $\mathrm{mTORC} 1$ and PCSK9 in mice. J Clin Invest 2012, 122: $1262-1270$
31. Hu D, Guo Y, Wu R, Shao T, Long J, Yu B, Wang H, Luo Y, Lu H, Zhang J, Chen YE, Peng D: New insight into metformin-induced cholesterol-lowering effect crosstalk between glucose and cholesterol homeostasis via ChREBP (carbohydrate-responsive element-binding protein)-mediated PCSK9 (proprotein convertase subtilisin/kexin type 9) regulation. Arterioscler Thromb Vasc Biol 2021, 41:e208-e223

32. Dietschy JM: Central nervous system: cholesterol turnover, brain development and neurodegeneration. Biol Chem 2009, 390: 287-293

33. O'Connell EM, Lohoff FW: Proprotein convertase subtilisin/kexin type 9 (PCSK9) in the brain and relevance for neuropsychiatric disorders. Front Neurosci 2020, 14:609

34. Poirier S, Prat A, Marcinkiewicz E, Paquin J, Chitramuthu BP, Baranowski D, Cadieux B, Bennett HP, Seidah NG: Implication of the proprotein convertase NARC-1/PCSK9 in the development of the nervous system. J Neurochem 2006, 98:838-850

35. Rousselet E, Marcinkiewicz J, Kriz J, Zhou A, Hatten ME, Prat A, Seidah NG: PCSK9 reduces the protein levels of the LDL receptor in mouse brain during development and after ischemic stroke. J Lipid Res 2011, 52:1383-1391

36. Mulder M, Koopmans G, Wassink G, Al Mansouri G, Simard ML, Havekes LM, Prickaerts J, Blokland A: LDL receptor deficiency results in decreased cell proliferation and presynaptic bouton density in the murine hippocampus. Neurosci Res 2007, $59: 251-256$

37. Kim J, Castellano JM, Jiang H, Basak JM, Parsadanian M, Pham V, Mason SM, Paul SM, Holtzman DM: Overexpression of low-density lipoprotein receptor in the brain markedly inhibits amyloid deposition and increases extracellular A beta clearance. Neuron 2009, 64: 632-644

38. Adorni MP, Ruscica M, Ferri N, Bernini F, Zimetti F: Proprotein convertase subtilisin/kexin type 9, brain cholesterol homeostasis and potential implication for Alzheimer's disease. Front Aging Neurosci 2019, 11:120

39. Jonas MC, Costantini C, Puglielli L: PCSK9 is required for the disposal of non-acetylated intermediates of the nascent membrane protein BACE1. EMBO Rep 2008, 9:916-922

40. Liu M, Wu G, Baysarowich J, Kavana M, Addona GH, Bierilo KK, Mudgett JS, Pavlovic G, Sitlani A, Renger JJ, Hubbard BK, Fisher TS, Zerbinatti CV: PCSK9 is not involved in the degradation of LDL receptors and BACE1 in the adult mouse brain. J Lipid Res 2010, 51:2611-2618

41. Williams DM, Finan C, Schmidt AF, Burgess S, Hingorani AD: Lipid lowering and Alzheimer disease risk: a mendelian randomization study. Ann Neurol 2020, 87:30-39

42. Bilousova T, Melnik M, Miyoshi E, Gonzalez BL, Poon WW, Vinters HV, Miller CA, Corrada MM, Kawas C, Hatami A, Albay R 3rd, Glabe C, Gylys KH: Apolipoprotein E/amyloid-beta complex accumulates in Alzheimer disease cortical synapses via apolipoprotein E receptors and is enhanced by APOE4. Am J Pathol 2019, 189:1621-1636

43. Zimetti F, Caffarra P, Ronda N, Favari E, Adorni MP, Zanotti I, Bernini F, Barocco F, Spallazzi M, Galimberti D, Ricci C, Ruscica M, Corsini A, Ferri N: Increased PCSK9 cerebrospinal fluid concentrations in Alzheimer's disease. J Alzheimers Dis 2017, 55: $315-320$

44. Lyall DM, Ward J, Banach M, Smith GD, Gill JG, Pell JP, Holmes MV, Sattar N: PCSK9 genetic variants and cognitive abilities: a large-scale Mendelian randomization study. Arch Med Sci 2021, 17:241-244

45. Gencer B, Mach F, Guo J, Im K, Ruzza A, Wang H, Kurtz CE, Pedersen TR, Keech AC, Ott BR, Sabatine MS, Giugliano RP; FOURIER Investigators: Cognition after lowering LDLcholesterol with evolocumab. J Am Coll Cardiol 2020, 75: 2283-2293 
46. di Mauro G, Zinzi A, Scavone C, Mascolo A, Gaio M, Sportiello L, Ferrajolo C, Rafaniello C, Rossi F, Capuano A: PCSK9 inhibitors and neurocognitive adverse drug reactions: analysis of individual case safety reports from the eudravigilance database. Drug Saf 2021, 44: 337-349

47. Macchi C, Favero C, Ceresa A, Vigna L, Conti DM, Pesatori AC, Racagni G, Corsini A, Ferri N, Sirtori CR, Buoli M, Bollati V, Ruscica M: Depression and cardiovascular risk-association among Beck Depression Inventory, PCSK9 levels and insulin resistance. Cardiovasc Diabetol 2020, 19:187

48. Nelson CP, Lai FY, Nath M, Ye S, Webb TR, Schunkert H, Samani NJ: Genetic assessment of potential long-term on-target side effects of PCSK9 (proprotein convertase subtilisin/kexin type 9) inhibitors. Circ Genom Precis Med 2019, 12:e002196

49. Kruth HS, Jones NL, Huang W, Zhao B, Ishii I, Chang J, Combs CA, Malide D, Zhang WY: Macropinocytosis is the endocytic pathway that mediates macrophage foam cell formation with native low density lipoprotein. J Biol Chem 2005, 280:2352-2360

50. Badimon L, Luquero A, Crespo J, Pena E, Borrell-Pages M: PCSK9 and LRP5 in macrophage lipid internalization and inflammation. Cardiovasc Res 2020, [E-pub ahead of print] doi: 10.1093/cvr/ cvaa254

51. Ding Z, Liu S, Wang X, Deng X, Fan Y, Shahanawaz J, Shmookler Reis RJ, Varughese KI, Sawamura T, Mehta JL: Cross-talk between LOX-1 and PCSK9 in vascular tissues. Cardiovasc Res 2015, 107: $556-567$

52. Ding Z, Liu S, Wang X, Deng X, Fan Y, Sun C, Wang Y, Mehta JL: Hemodynamic shear stress via ROS modulates PCSK9 expression in human vascular endothelial and smooth muscle cells and along the mouse aorta. Antioxid Redox Signal 2015, 22:760-771

53. Liu S, Deng X, Zhang P, Wang X, Fan Y, Zhou S, Mu S, Mehta JL, Ding Z: Blood flow patterns regulate PCSK9 secretion via MyD88mediated pro-inflammatory cytokines. Cardiovasc Res 2020, 116 : $1721-1732$

54. Leucker TM, Gerstenblith G, Schar M, Brown TT, Jones SR, Afework Y, Weiss RG, Hays AG: Evolocumab, a PCSK9monoclonal antibody, rapidly reverses coronary artery endothelial dysfunction in people living with HIV and people with dyslipidemia. J Am Heart Assoc 2020, 9:e016263

55. Giunzioni I, Tavori H, Covarrubias R, Major AS, Ding L, Zhang Y, DeVay RM, Hong L, Fan D, Predazzi IM, Rashid S, Linton MF, Fazio S: Local effects of human PCSK9 on the atherosclerotic lesion. J Pathol 2016, 238:52-62

56. Ricci C, Ruscica M, Camera M, Rossetti L, Macchi C, Colciago A, Zanotti I, Lupo MG, Adorni MP, Cicero AFG, Fogacci F, Corsini A, Ferri N: PCSK9 induces a pro-inflammatory response in macrophages. Sci Rep 2018, 8:2267

57. Tang ZH, Peng J, Ren Z, Yang J, Li TT, Li TH, Wang Z, Wei DH, Liu LS, Zheng XL, Jiang ZS: New role of PCSK9 in atherosclerotic inflammation promotion involving the TLR4/NF-kappaB pathway. Atherosclerosis 2017, 262:113-122

58. Sun H, Krauss RM, Chang JT, Teng BB: PCSK9 deficiency reduces atherosclerosis, apolipoprotein B secretion, and endothelial dysfunction. J Lipid Res 2018, 59:207-223

59. Ding Z, Liu S, Wang X, Theus S, Deng X, Fan Y, Zhou S, Mehta JL: PCSK9 regulates expression of scavenger receptors and ox-LDL uptake in macrophages. Cardiovasc Res 2018, 114: $1145-1153$

60. Liu D, Zeng X, Li X, Cui C, Hou R, Guo Z, Mehta JL, Wang $X$ : Advances in the molecular mechanisms of NLRP3 inflammasome activators and inactivators. Biochem Pharmacol 2020, 175:113863

61. Back M, Yurdagul A Jr, Tabas I, Oorni K, Kovanen PT: Inflammation and its resolution in atherosclerosis: mediators and therapeutic opportunities. Nat Rev Cardiol 2019, 16:389-406
62. Ruscica M, Tokgozoglu L, Corsini A, Sirtori CR: PCSK9 inhibition and inflammation: a narrative review. Atherosclerosis 2019, 288: $146-155$

63. Macchi C, Ferri N, Favero C, Cantone L, Vigna L, Pesatori AC, Lupo MG, Sirtori CR, Corsini A, Bollati V, Ruscica M: Long-term exposure to air pollution raises circulating levels of proprotein convertase subtilisin/kexin type 9 in obese individuals. Eur J Prev Cardiol 2019, 26:578-588

64. Ding Z, Wang X, Liu S, Zhou S, Kore RA, Mu S, Deng X, Fan Y, Mehta JL: NLRP3 inflammasome via IL-1beta regulates PCSK9 secretion. Theranostics 2020, 10:7100-7110

65. Kuhnast S, van der Hoorn JW, Pieterman EJ, van den Hoek AM, Sasiela WJ, Gusarova V, Peyman A, Schafer HL, Schwahn U, Jukema JW, Princen HM: Alirocumab inhibits atherosclerosis, improves the plaque morphology, and enhances the effects of a statin. J Lipid Res 2014, 55:2103-2112

66. Landlinger $\mathrm{C}$, Pouwer MG, Juno C, van der Hoorn JWA, Pieterman EJ, Jukema JW, Staffler G, Princen HMG, Galabova G: The AT04A vaccine against proprotein convertase subtilisin/kexin type 9 reduces total cholesterol, vascular inflammation, and atherosclerosis in APOE*3Leiden.CETP mice. Eur Heart J 2017, 38: 2499-2507

67. Wu D, Pan Y, Yang S, Li C, Zhou Y, Wang Y, Chen X, Zhou Z, Liao Y, Qiu Z: PCSK9Qbeta-003 vaccine attenuates atherosclerosis in apolipoprotein E-deficient mice. Cardiovasc Drugs Ther 2021, 35: $141-151$

68. Ouguerram K, Chetiveaux M, Zair Y, Costet P, Abifadel M, Varret M, Boileau C, Magot T, Krempf M: Apolipoprotein B100 metabolism in autosomal-dominant hypercholesterolemia related to mutations in PCSK9. Arterioscler Thromb Vasc Biol 2004, 24: $1448-1453$

69. Dijk W, Le May C, Cariou B: Beyond LDL: what role for PCSK9 in triglyceride-rich lipoprotein metabolism? Trends Endocrinol Metab 2018, 29:420-434

70. Lambert G, Jarnoux AL, Pineau T, Pape O, Chetiveaux M, Laboisse C, Krempf M, Costet P: Fasting induces hyperlipidemia in mice overexpressing proprotein convertase subtilisin kexin type 9: lack of modulation of very-low-density lipoprotein hepatic output by the low-density lipoprotein receptor. Endocrinology 2006, 147: 4985-4995

71. Sun H, Samarghandi A, Zhang N, Yao Z, Xiong M, Teng BB: Proprotein convertase subtilisin/kexin type 9 interacts with apolipoprotein B and prevents its intracellular degradation, irrespective of the low-density lipoprotein receptor. Arterioscler Thromb Vasc Biol 2012, 32:1585-1595

72. Herbert B, Patel D, Waddington SN, Eden ER, McAleenan A, Sun XM, Soutar AK: Increased secretion of lipoproteins in transgenic mice expressing human D374Y PCSK9 under physiological genetic control. Arterioscler Thromb Vasc Biol 2010, 30:1333-1339

73. Kanji R, Kubica J, Navarese EP, Gorog DA: Endogenous fibrinolysis-relevance to clinical thrombosis risk assessment. Eur J Clin Invest 2020, 51:e13471

74. Burchardt P, Rzezniczak J, Dudziak J, Dzumak A, Marchlewski T, Ganowicz-Kaatz T, Popiak M, Slomczynski M, Jezierski M, Laskowski W, Luczak T, Plewa R: Evaluation of plasma PCSK9 concentrations, transcript of LDL receptor, as well as the total number of monocyte LDL receptors in acute coronary syndrome patients. Cardiol J 2016, 23:604-609

75. Cariou B, Guerin P, Le May C, Letocart V, Arnaud L, Guyomarch B, Pichelin M, Probst V: Circulating PCSK9 levels in acute coronary syndrome: results from the PC-SCA-9 prospective study. Diabetes Metab 2017, 43:529-535

76. Navarese EP, Kolodziejczak M, Winter MP, Alimohammadi A, Lang IM, Buffon A, Lip GY, Siller-Matula JM: Association of PCSK9 with platelet reactivity in patients with acute coronary 
syndrome treated with prasugrel or ticagrelor: the PCSK9-REACT study. Int J Cardiol 2017, 227:644-649

77. Camera M, Rossetti L, Barbieri SS, Zanotti I, Canciani B, Trabattoni D, Ruscica M, Tremoli E, Ferri N: PCSK9 as a positive modulator of platelet activation. J Am Coll Cardiol 2018, 71: 952-954

78. Wang H, Wang Q, Wang J, Guo C, Kleiman K, Meng H, Knight JS, Eitzman DT: Proprotein convertase subtilisin/kexin type 9 (PCSK9) deficiency is protective against venous thrombosis in mice. Sci Rep 2017, 7:14360

79. Qi Z, Hu L, Zhang J, Yang W, Liu X, Jia D, Yao Z, Chang L, Pan G, Zhong H, Luo X, Yao K, Sun A, Qian J, Ding Z, Ge J: PCSK9 (proprotein convertase subtilisin/kexin 9) enhances platelet activation, thrombosis, and myocardial infarct expansion by binding to platelet CD36. Circulation 2021, 143:45-61

80. Cariou B, Si-Tayeb K, Le May C: Role of PCSK9 beyond liver involvement. Curr Opin Lipidol 2015, 26:155-161

81. Le May C, Kourimate S, Langhi C, Chetiveaux M, Jarry A, Comera C, Collet X, Kuipers F, Krempf M, Cariou B, Costet P. Proprotein convertase subtilisin kexin type 9 null mice are protected from postprandial triglyceridemia. Arterioscler Thromb Vasc Biol 2009, 29:684-690

82. Garcon D, Moreau F, Ayer A, Dijk W, Prieur X, Arnaud L, Roubtsova A, Seidah N, Prat A, Cariou B, Le May C: Circulating rather than intestinal PCSK9 (proprotein convertase subtilisin kexin type 9) regulates postprandial lipemia in mice. Arterioscler Thromb Vasc Biol 2020, 40:2084-2094

83. Ooi TC, Krysa JA, Chaker S, Abujrad H, Mayne J, Henry K, Cousins M, Raymond A, Favreau C, Taljaard M, Chretien M, Mbikay M, Proctor SD, Vine DF: The effect of PCSK9 loss-offunction variants on the postprandial lipid and ApoB-lipoprotein response. J Clin Endocrinol Metab 2017, 102:3452-3460

84. Rashid S, Tavori H, Brown PE, Linton MF, He J, Giunzioni I, Fazio S: Proprotein convertase subtilisin kexin type 9 promotes intestinal overproduction of triglyceride-rich apolipoprotein B lipoproteins through both low-density lipoprotein receptor-dependent and -independent mechanisms. Circulation 2014, 130:431-441

85. Levy E, Ben Djoudi Ouadda A, Spahis S, Sane AT, Garofalo C, Grenier E, Emonnot L, Yara S, Couture P, Beaulieu JF, Menard D, Seidah NG, Elchebly M: PCSK9 plays a significant role in cholesterol homeostasis and lipid transport in intestinal epithelial cells. Atherosclerosis 2013, 227:297-306

86. Le May C, Berger JM, Lespine A, Pillot B, Prieur X, Letessier E, Hussain MM, Collet X, Cariou B, Costet P: Transintestinal cholesterol excretion is an active metabolic process modulated by PCSK9 and statin involving ABCB1. Arterioscler Thromb Vasc Biol 2013, 33:1484-1493

87. Mbikay M, Sirois F, Mayne J, Wang GS, Chen A, Dewpura T, Prat A, Seidah NG, Chretien M, Scott FW: PCSK9-deficient mice exhibit impaired glucose tolerance and pancreatic islet abnormalities. FEBS Lett 2010, 584:701-706

88. Langhi C, Le May C, Gmyr V, Vandewalle B, Kerr-Conte J, Krempf M, Pattou F, Costet P, Cariou B: PCSK9 is expressed in pancreatic delta-cells and does not alter insulin secretion. Biochem Biophys Res Commun 2009, 390:1288-1293

89. Da Dalt L, Ruscica M, Bonacina F, Balzarotti G, Dhyani A, Di Cairano E, Baragetti A, Arnaboldi L, De Metrio S, Pellegatta F, Grigore L, Botta M, Macchi C, Uboldi P, Perego C, Catapano AL, Norata GD: PCSK9 deficiency reduces insulin secretion and promotes glucose intolerance: the role of the low-density lipoprotein receptor. Eur Heart J 2019, 40:357-368

90. Mbikay M, Sirois F, Gyamera-Acheampong C, Wang GS, Rippstein P, Chen A, Mayne J, Scott FW, Chretien M: Variable effects of gender and Western diet on lipid and glucose homeostasis in aged PCSK9-deficient C57BL/6 mice CSK9PC57BL/6. J Diabetes 2015, 7:74-84
91. Ramin-Mangata S, Thedrez A, Nativel B, Diotel N, Blanchard V, Wargny M, Aguesse A, Billon-Crossouard S, Vindis C, Le May C, Hulin P, Armanet M, Gmyr V, Pattou F, Croyal M, Meilhac O, Nobécourt E, Cariou B, Lambert G: Effects of proprotein convertase subtilisin kexin type 9 modulation in human pancreatic beta cells function. Atherosclerosis 2021, 326:47-55

92. Peyot ML, Roubtsova A, Lussier R, Chamberland A, Essalmani R, Murthy Madiraju SR, Seidah NG, Prentki M, Prat A: Substantial PCSK9 inactivation in $\beta$-cells does not modify glucose homeostasis or insulin secretion in mice. Biochim Biophys Acta Mol Cell Biol Lipids 2021, 866:158968

93. Bordicchia M, Spannella F, Ferretti G, Bacchetti T, Vignini A, Di Pentima C, Mazzanti L, Sarzani R: PCSK9 is expressed in human visceral adipose tissue and regulated by insulin and cardiac natriuretic peptides. Int J Mol Sci 2019, 20:245

94. Baragetti A, Balzarotti G, Grigore L, Pellegatta F, Guerrini U, Pisano G, Fracanzani AL, Fargion S, Norata GD, Catapano AL: PCSK9 deficiency results in increased ectopic fat accumulation in experimental models and in humans. Eur J Prev Cardiol 2017, 24:1870-1877

95. Roubtsova A, Munkonda MN, Awan Z, Marcinkiewicz J, Chamberland A, Lazure C, Cianflone K, Seidah NG, Prat A: Circulating proprotein convertase subtilisin/kexin 9 (PCSK9) regulates VLDLR protein and triglyceride accumulation in visceral adipose tissue. Arterioscler Thromb Vasc Biol 2011, 31:785-791

96. Cyr Y, Lamantia V, Bissonnette S, Burnette M, Besse-Patin A, Demers A, Wabitsch M, Chretien M, Mayer G, Estall JL, Saleh M, Faraj M: Lower plasma PCSK9 in normocholesterolemic subjects is associated with upregulated adipose tissue surface-expression of LDLR and CD36 and NLRP3 inflammasome. Physiol Rep 2021, 9: e14721

97. Dozio E, Ruscica M, Vianello E, Macchi C, Sitzia C, Schmitz G, Tacchini L, Corsi Romanelli MM: PCSK9 expression in epicardial adipose tissue: molecular association with local tissue inflammation. Mediators Inflamm 2020, 2020:1348913

98. Uceda DE, Zhu XY, Woollard JR, Ferguson CM, Patras I, Carlson DF, Asirvatham SJ, Lerman A, Lerman LO: Accumulation of pericardial fat is associated with alterations in heart rate variability patterns in hypercholesterolemic pigs. Circ Arrhythm Electrophysiol 2020, 13:e07614

99. Ruscica M, Baragetti A, Catapano AL, Norata GD: Translating the biology of adipokines in atherosclerosis and cardiovascular diseases: gaps and open questions. Nutr Metab Cardiovasc Dis 2017, 27: 379-395

100. Sun L, Yang X, Li Q, Zeng P, Liu Y, Liu L, Chen Y, Yu M, Ma C, Li X, Li Y, Zhang R, Zhu Y, Miao QR, Han J, Duan Y: Activation of adiponectin receptor regulates proprotein convertase subtilisin/kexin type 9 expression and inhibits lesions in ApoE-deficient mice. Arterioscler Thromb Vasc Biol 2017, 37:1290-1300

101. Macchi C, Greco MF, Botta M, Sperandeo P, Dongiovanni P, Valenti L, Cicero AFG, Borghi C, Lupo MG, Romeo S, Corsini A, Magni P, Ferri N, Ruscica M, Leptin: Resistin, and proprotein convertase subtilisin/kexin type 9: the role of STAT3. Am J Pathol 2020, 190:2226-2236

102. Levenson AE, Haas ME, Miao J, Brown RJ, de Ferranti SD, Muniyappa R, Biddinger SB: Effect of leptin replacement on PCSK9 in ob/ob mice and female lipodystrophic patients. Endocrinology 2016, 157:1421-1429

103. Melone M, Wilsie L, Palyha O, Strack A, Rashid S: Discovery of a new role of human resistin in hepatocyte low-density lipoprotein receptor suppression mediated in part by proprotein convertase subtilisin/kexin type 9. J Am Coll Cardiol 2012, 59:1697-1705

104. Huang B, Song BL, Xu C: Cholesterol metabolism in cancer: mechanisms and therapeutic opportunities. Nat Metab 2020, 2: 132-141

105. Nowak C, Arnlov J: A Mendelian randomization study of the effects of blood lipids on breast cancer risk. Nat Commun 2018, 9:3957 
106. Momtazi-Borojeni AA, Nik ME, Jaafari MR, Banach M, Sahebkar A: Potential anti-tumor effect of a nanoliposomal antiPCSK9 vaccine in mice bearing colorectal cancer. Arch Med Sci 2019, 15:559-569

107. Momtazi-Borojeni AA, Nik ME, Jaafari MR, Banach M, Sahebkar A: Effects of immunization against PCSK9 in an experimental model of breast cancer. Arch Med Sci 2019, 15: $570-579$

108. Xu X, Cui Y, Cao L, Zhang Y, Yin Y, Hu X: PCSK9 regulates apoptosis in human lung adenocarcinoma A549 cells via endoplasmic reticulum stress and mitochondrial signaling pathways. Exp Ther Med 2017, 13:1993-1999

109. Liu X, Bao X, Hu M, Chang H, Jiao M, Cheng J, Xie L, Huang Q, Li F, Li CY: Inhibition of PCSK9 potentiates immune checkpoint therapy for cancer. Nature 2020, 588:693-698
110. Perrot N, Valerio V, Moschetta D, Boekholdt SM, Dina C, Chen HY, Abner E, Martinsson A, Manikpurage HD, Rigade S, Capoulade R, Mass E, Clavel MA, Le Tourneau T, Messika-Zeitoun D, Wareham NJ, Engert JC, Polvani G, Pibarot P, Esko T, Smith JG, Mathieu P, Thanassoulis G, Schott JJ, Bosse Y, Camera M, Theriault S, Poggio P, Arsenault BJ: Genetic and in vitro inhibition of PCSK9 and calcific aortic valve stenosis. JACC Basic Transl Sci 2020, 5:649-661

111. Maarouf N, Chen YX, Shi C, Deng J, Diao C, Rosin M, Shrivastava V, Batulan Z, Liu J, O'Brien ER: Unlike estrogens that increase PCSK9 levels post-menopause HSP27 vaccination lowers cholesterol levels and atherogenesis due to divergent effects on PCSK9 and LDLR. Pharmacol Res 2020, 161:105222

112. Silverstein RL: PCSK9 (proprotein convertase subtilisin/kexin 9) goes "DAMP.". Circulation 2021, 143:62-64 